\title{
Capacity to Develop Recycled Aggregate Concrete in South East Asia
}

\author{
Natt Makul ${ }^{1}\left(\mathbb{D}\right.$, Roman Fediuk 2,*(D), Mugahed Amran 3,4 ${ }^{(D)}$, Abdullah M. Zeyad ${ }^{5}$, \\ Afonso Rangel Garcez de Azevedo ${ }^{6}$ (D), Sergey Klyuev ${ }^{7}$ (D) Nikolai Vatin ${ }^{8}$ iD and Maria Karelina 9
}

Citation: Makul, N.; Fediuk, R.; Amran, M.; Zeyad, A.M.; de Azevedo, A.R.G.; Klyuev, S.; Vatin, N.; Karelina, M. Capacity to Develop Recycled Aggregate Concrete in South East Asia. Buildings 2021, 11, 234. https://doi.org/10.3390/ buildings11060234

Academic Editor: Giuseppina Uva

Received: 7 May 2021

Accepted: 28 May 2021

Published: 30 May 2021

Publisher's Note: MDPI stays neutral with regard to jurisdictional claims in published maps and institutional affiliations.

Copyright: (c) 2021 by the authors. Licensee MDPI, Basel, Switzerland. This article is an open access article distributed under the terms and conditions of the Creative Commons Attribution (CC BY) license (https:// creativecommons.org/licenses/by/ $4.0 /)$.
1 Department of Civil Engineering Technology, Faculty of Industrial Technology, Phranakhon Rajabhat University, Bangkok 10220, Thailand; natt@pnru.ac.th

2 Polytechnic Institute, Far Eastern Federal University, 690922 Vladivostok, Russia

3 Department of Civil Engineering, College of Engineering, Prince Sattam Bin Abdulaziz University, Alkharj 11942, Saudi Arabia; mugahed_amran@hotmail.com

4 Department of Civil Engineering, Faculty of Engineering and IT, Amran University, Quhal, Amran 9677, Yemen

5 Department of Civil Engineering, Faculty of Engineering, Jazan University, Jizan 88723, Saudi Arabia; a.zeyad@jazanuni.ed.sa

6 Civil Engineering Laboratory (LECIV), State University of the Northern Rio de Janeiro (UENF), Av. Alberto Lamego, 2000, Campos dos Goytacazes 28013-602, Brazil; afonso.garcez91@gmail.com

7 Department of Theoretical Mechanics and Strength of Materials, Belgorod State Technological University named after V.G. Shukhov, 308012 Belgorod, Russia; klyuyev@yandex.ru

8 Institute of Civil Engineering, Peter the Great Saint Petersburg Polytechnic University, 195251 Saint Petersburg, Russia; vatin@mail.ru

9 MADI Department of Machine Parts and Theory of Mechanisms,

Moscow Automobile and Road Construction University, 125319 Moscow, Russia; Karelinamu@mail.ru

* Correspondence: fedyuk.rs@dvfu.ru

Abstract: The global sustainable construction aimed to minimize the ecological impacts of constructed facilities' lifetime. In construction, concretes are the major materials utilized in South East Asia. Thus, it makes environmental and economic sense to utilize recycled materials in the production of new concretes for diverse uses. This review indicated that the practical implementations of the recycled aggregate concretes (RAC) in the area is greatly lacking, even though there are reasonable studies on RAC, particularly because of lack awareness and economic viability of such uses at the present period. This research aims to establish an interdisciplinary consortium with researchers, policy makers, practitioners, and social scientists in Southeast Asia to investigate the development of sustainable, durable, cost-effective, green concrete by utilizing recycled aggregates. Concentrating on waste resource recovery, this research presents an integrated modeling method. The approaches track and forecast a variety of values across technical, economic, social, and environmental areas linking these to the material flow and therefore integrating and building upon one-dimensional models like life cycle assessments (LCAs) and material flow analyses (MFAs). Additionally, the analysis of this study supported the recycling of cement for general use in construction, emphasizing the feasibility, reliability, and longevity of a project at the same time. However, the analysis also demonstrated that although there is fair progress on recycled concrete, there is still a severe lack of appropriate development in particular because of the lack of economic sustainability and knowledge of such applications at present. Raw material conservations were recorded; carbon dioxide costs and footprint were also reduced. Considering the RAC economic, technical, and environmental parameters, frameworks were applied for sustainable selections with target compressive strengths as the major goal.

Keywords: recycled aggregate concrete; capacity; capability building; South East Asia; structure formation

\section{Introduction}

The production and application of concrete for use in buildings is present all over the world, regardless of the country's economic and geographic condition, having Portland 
cement in its composition, which is the second most consumed material in the world, just behind water as well as water and aggregates [1]. Thus, considering its high consumption worldwide, research seeks to evaluate various conditions of technological performance [2], durability [3], potential for the application of new materials [4], and issues related to its sustainability [5] in various cement-based materials, such as concrete and mortars. South East Asia has more than 650 million inhabitants, more than $50 \%$ of whom live in cities [6], and that went through a strong urbanization process in the 1980s and 1990s through large urban megaprojects [7], which has been developing until today, with investments that vary between $3 \%$ to $14 \%$ of the countries budgets, being one of the pillars of the strong economic development of the region that promotes an increasing consumption of concrete [8]. It is estimated that 1.6 billion tons of construction and demolition waste (CDW) was generated annually in China in 2016, and waste concrete made up the majority of it; the global aggregate production is shown in Figure 1.

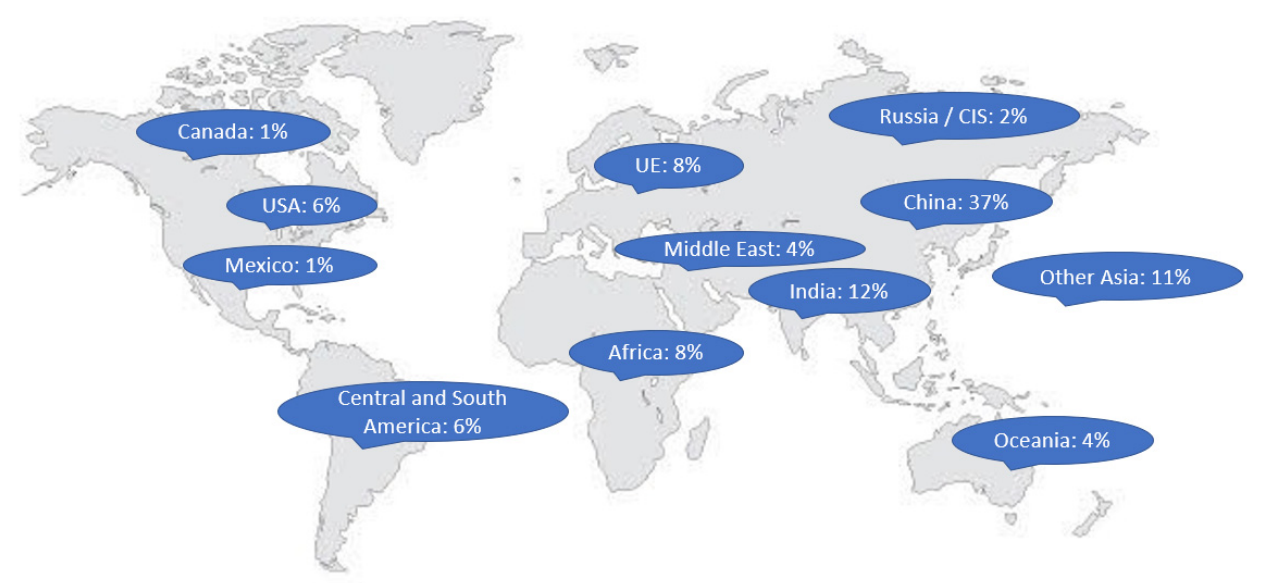

Figure 1. Global production of aggregate (2015-2020) [9-12].

Construction and demolition waste is one of the main sources for the production of recycled aggregates worldwide, due to its high availability and compatibility $[13,14]$. As South East Asia has several countries, in different economic conditions, it is difficult to accurately measure data related to the production of CDW; Malaysia, Singapore, and Vietnam are the only countries that publish data on a regular basis [6]. Another way of presenting the construction and demolition waste generation data indicates the quantity of CDW weighted by construction value (per annum), which is a more realistic form of data of the local reality and of better comparative analysis, and also the quantity of CDW per added value construction industry, as can be seen in Table 1 below.

Table 1. Ways of quantifying CDW in some countries and regions [15-17].

\begin{tabular}{ccc}
\hline Country & $\begin{array}{c}\text { Quantity of CDW Weighted } \\
\text { by Construction Value }\end{array}$ & $\begin{array}{c}\text { Quantity of CDW by Value } \\
\text { Added in the Construction } \\
\text { Industry }\end{array}$ \\
\hline Myanmar & 9.49 million ton. & 10 tons per million dollars \\
\hline Thailand & 7.2 million ton. & 693 tons per million dollars \\
\hline Vietnam & 8.8 million ton. & 933 tons per million dollars \\
\hline China & 1130 million ton. & 1547 tons per million dollars \\
\hline South East Asian average & 5.37 million ton. & 472 tons per million dollars \\
\hline USA & 534 million ton. & 839 tons per million dollars \\
\hline
\end{tabular}

The use of recycled aggregates in concrete brings a series of technological and environmental benefits; however, one of the biggest criticisms about their use on a large scale refers 
to the great heterogeneity of their composition, especially those from CDW, as they contain not only concrete, but also other building materials, such as brick, wood, plaster, etc. [13]. There is some research that shows techniques for separating and pretreating CDWs before they are crushed for the purpose of use as recycled aggregate, such as the use of electromagnets to separate metallic parts, for example, common in concrete structures [18]. Another study evaluated the use of mixed recycled aggregates in mortars, evaluating the effect of temporal variability in the collection of materials and their influence on the final properties of mortars, using statistical models for this. The results of this research showed that adequate and standardized processing, in addition to defining mixtures in an optimized way, considerably reduced the effect of the heterogeneity of recycled aggregates on the technological properties of mortars [13,19].

The diffusion of the use of recycled aggregates is directly related to sustainability issues, which enable a more optimized use of natural resources. Considering the high use of concrete all over the world, the demand for the aggregates of different diameters, extracted from natural rocks and/or river beds (sand and gravel), causes a series of environmental damages; additionally, in the not-so-distant future, the scarcity of these natural resources is clear, which will certainly cause serious economic damage, especially to the countries of South East Asia, where there is still a great prospect of growth in the coming decades, thus justifying the need for research in this field [20].

In the specific case of the countries of South East Asia and others nearby, the scarcity of mineral resources for the production of natural aggregates for civil construction and the problems related to the limitation of physical space for disposal of waste in landfills leads to the need to search for recycled building materials, using the waste that would be discarded in their composition [21,22]. Even in larger countries, such as Russia and China, environmental issues are evident, promoting much research related to recycled aggregates [23,24]. The concretes that use recycled aggregates have in their mechanical properties a multiaxial state of stresses, similar to real situations of use, still needing deepening related to the interaction between beams and columns and their behavior in execution situations in places of movement of tectonic plates [25]. The buildings emit carbon in several stages throughout their construction process, as can be exemplified in Figure 2.

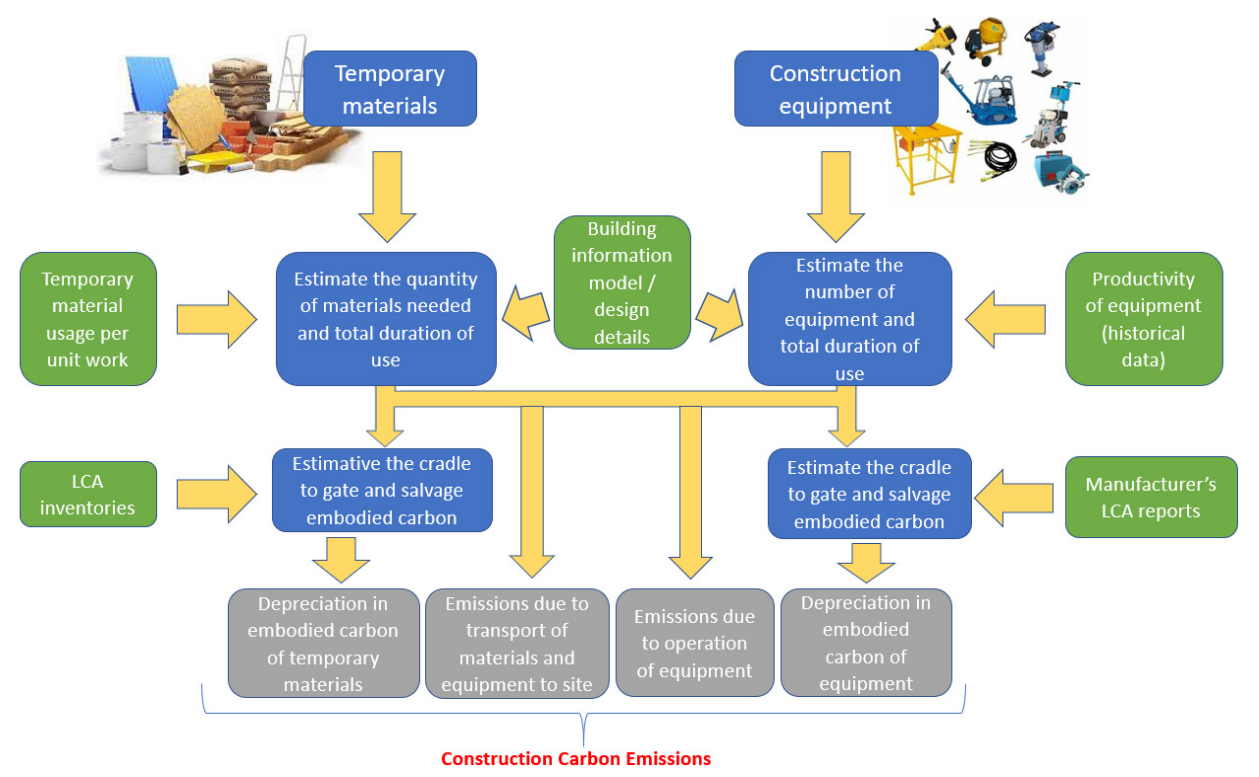

Figure 2. A framework for the estimation of carbon emissions incurred during the construction phase [26-28].

The paper [29] cited different research studies on recycled materials on concrete for building construction. It explored the feasibility, sustainability, technical improvement, durability, and economical evaluation aspects of the particular concrete. Four concrete 
formulations were analyzed: recycled aggregate concrete, recycled aggregate mortars, self-compacting concrete containing rubble powder, and reuse of glass-reinforced plastic industrial waste in cementitious products. One finding is that recycled-aggregate compressive strength, by addition of fly ash as a fine aggregate replacement, can be improved to be equal to or greater than that of natural-aggregate concrete. Figure 3 depicts the typical recycled aggregates. Many slags, sludge, and scales are produced and stored in the landfills and may be used as an aggregate.

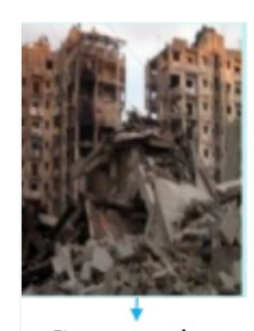

Construction and demolition

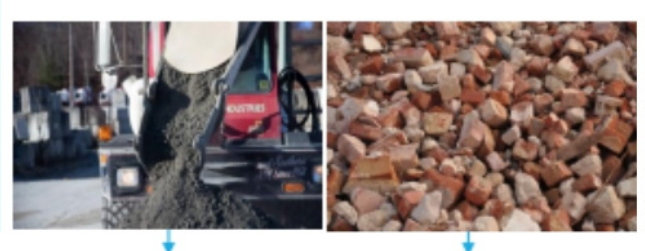

Returned concrete from ready mix trucks

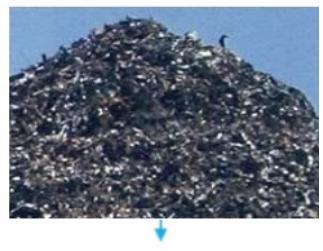

Metallurgical waste waste

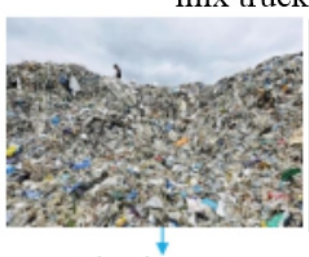

Plastic waste

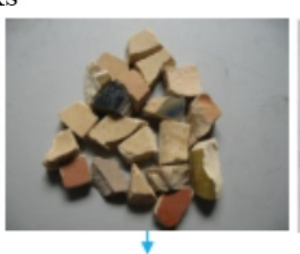

Ceramic waste

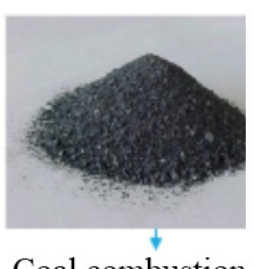

Coal combustion waste

Figure 3. Typical recycled aggregates.

The economy of most the South East Asian nations depends to a great level on the infrastructure activities and the construction sector apart from the gas and oil sectors [30]. This is because of recent initiatives taken by the local governments to diversify from gas and oil sectors to attain dependent economies. In the Arab Construction World magazines, published data show that the total values of real estate projects presently under constructions in the South East Asia stand over $\$ 3$ trillion [31]. In South East Asia, the major construction industry aspects that have notable impacts on the environment are scarce useable virgin aggregates for generating concretes, lack of iron ores for making steels, and limited fresh water sources.

The construction and building sector is poised for a new rapid growth phase alongside deployments of digital technologies with South East Asian countries set to overtake developed economies [9]. The ingredients to make concretes are in high demand and are thus in short supply as concretes are the favored materials of choice in different performance, forms, and characteristics for the upcoming infrastructures. This exerts great pressure on natural concretes and increases the construction costs. The sustainability of virgin concretes should therefore be attained through capability and capacity building to develop reclaimed aggregate concretes. It is crucial to cautiously assess the concrete life cycle as South East Asian nations move to circular economies [32]. Any dismantled concretes should be reclaimed and reused in the systems for application as aggregates, minimizing the embodied concrete carbon [33]. Figure 4 shows the expected reduction of the carbon footprint globally [34-37]. 


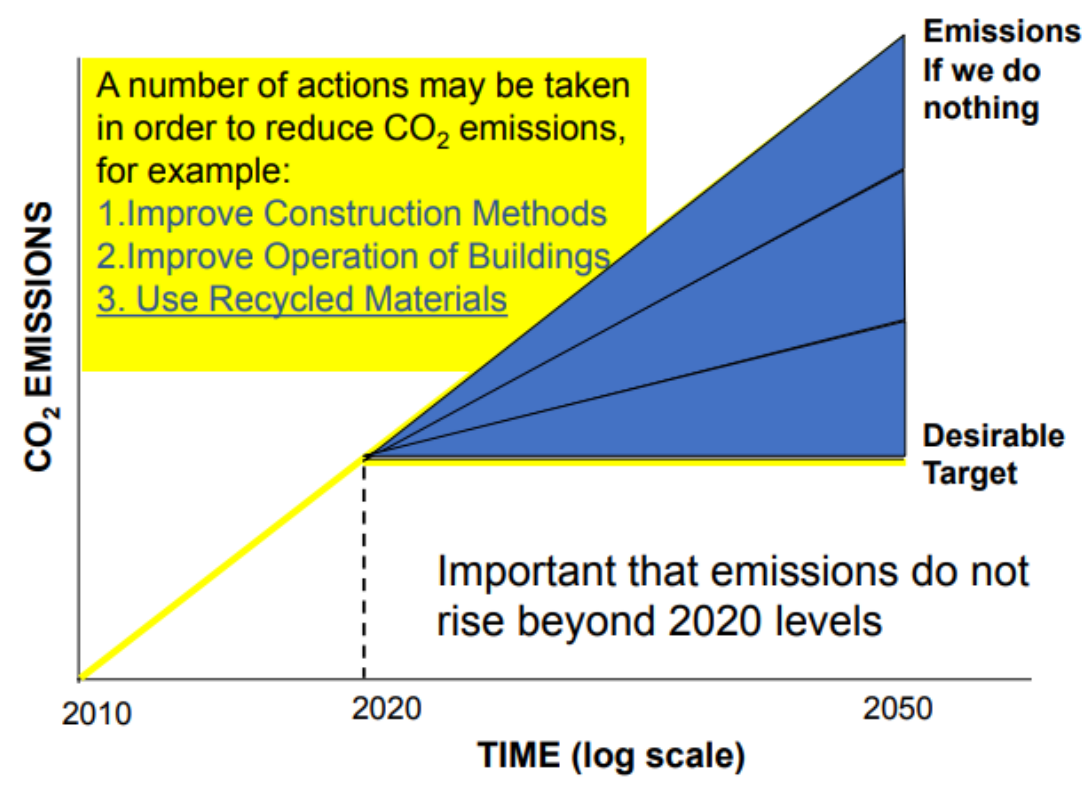

Figure 4. Expected reduction on the carbon footprint globally $[34,36,37]$.

The construction sector's importance for the three sustainable development elements, namely effective environment protection, economic growth, and social progress, cannot be overlooked [38]. This work aims to evolve theoretical frameworks for implementing sustainability strategies and standards to the building and construction sector from lifecycle perspectives to contribute to sustainable development. The frameworks depend on three fundamental principles that design for environments and humans, resource management, and life cycle designs. Each principle involving methods and strategies to be used during the life cycle of construction projects is discussed following a literature review. For clarity, a few case studies are presented on the approaches [35]. The frameworks providing tools for construction industry stakeholders also aim to help in developing the most relevant examination tools that are based on the critical condition.

South East Asia is usually viewed as an area that has inadequate natural resources needed for the production of concretes. Concretes consist of four major ingredients: aggregates, sand, cement, and water. Water is domestically available but is desalinated for the most part. While in certain nations, concrete batching factories reuse the water they utilize for cleaning, this is limited in South East Asia [39]. The raw materials are usually imported from other nations, while concretes are generated locally. Demands have exceeded supplies at peak market levels. Therefore, some cement quantities have to be imported to supplement domestic demands.

\section{Significance of the Study}

This study's significance lies in its discussion of several solutions and methods and one of the recommended techniques, which are the reuse of cement for general use in construction, emphasizing the feasibility, quality, and longevity of such a project at the same time. According to Mehta [40], those solutions would certainly increase the technical sustainability of concrete as a building material. However, in order to move towards ecological sustainability, it has also been claimed that by dramatically reducing the unsustainable use of resources, thereby dramatic changes in our production efficiency must be made, such as improving the composition of concrete to be renewable and sustainable (Figure 5). This suggests that by implementing the "making do with less" strategy, the long-term response to the sustainability issue of modern building materials lies in significantly enhancing their durability [41]. At this juncture, if the business-as-usual strategy persists for the building industry and community, it would hit the limit where the natural support structures are irreversibly impaired. 


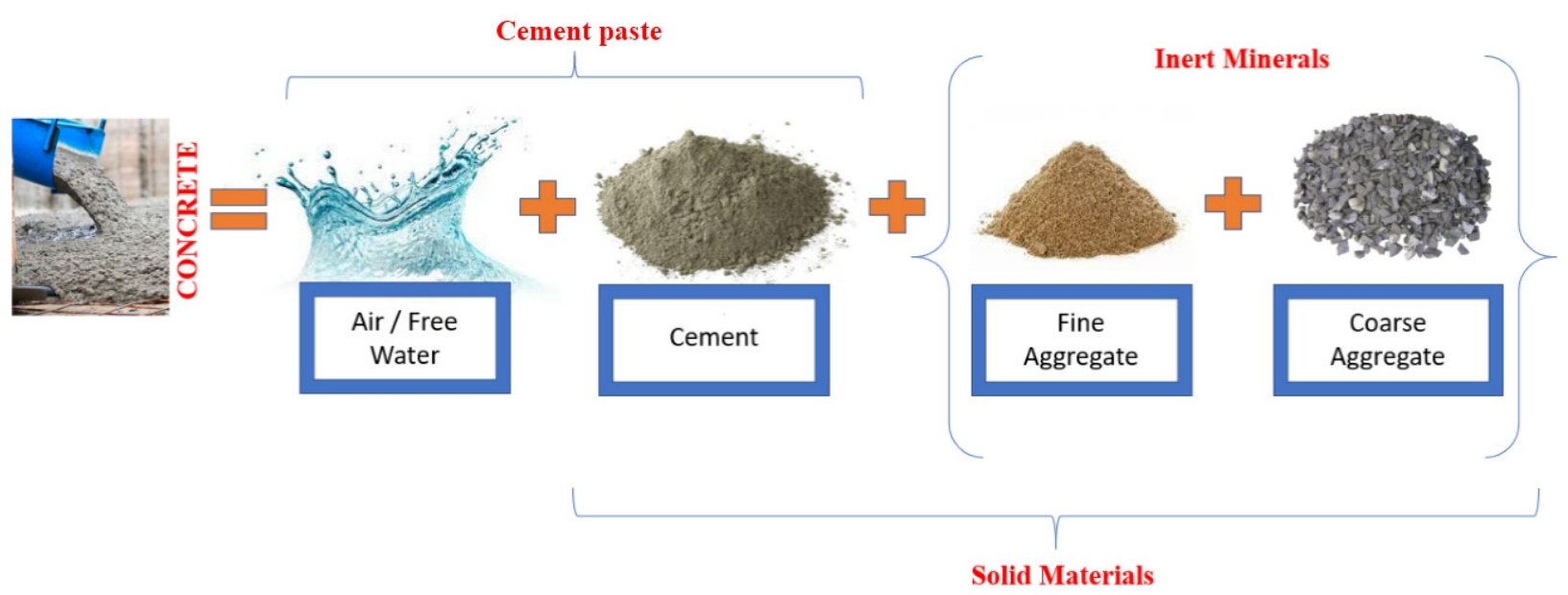

Figure 5. Basics materials of concrete composition.

\section{Sustainable Constructions in South East Asia}

A researcher noticed how sustainability is an ongoing trend in all sectors of the economy, especially in construction, as cement and by extension, concrete, or in general, the construction industry, is one of the most prominent contributors to greenhouse gas emissions and the urbanization of green spaces [42]. It is good that as a species, we use our collective knowledge and effort to sustain the planet within its boundaries to support life. This article proved how we are going to progress in the future, envisioning the future not as futuristic, but an environment-friendly utopia as we learn to manage Earth's resources to sustain our ever-increasing population [43]. We should see more studies like these appear, but what the researcher would expect is the first building that would implement these innovations.

In recent years, the issues of sustainable construction have become an important topic [44]. This research study is helpful in the future manufacturing of a concrete by using recycled aggregate [45], towards expanding the suitable use of materials as a way to maintainable construction practice (Figure 6). Due to the increasing negative effects of climate change, the most utilized material in construction, which is concrete, will be sustainable enough to be eco-friendly. The researchers ought to compare the naturalaggregate and recycled-aggregates; there was much information that was discussed about recycled aggregate and fly ash, its particles, and how it would be beneficial [46].

$100 \%$

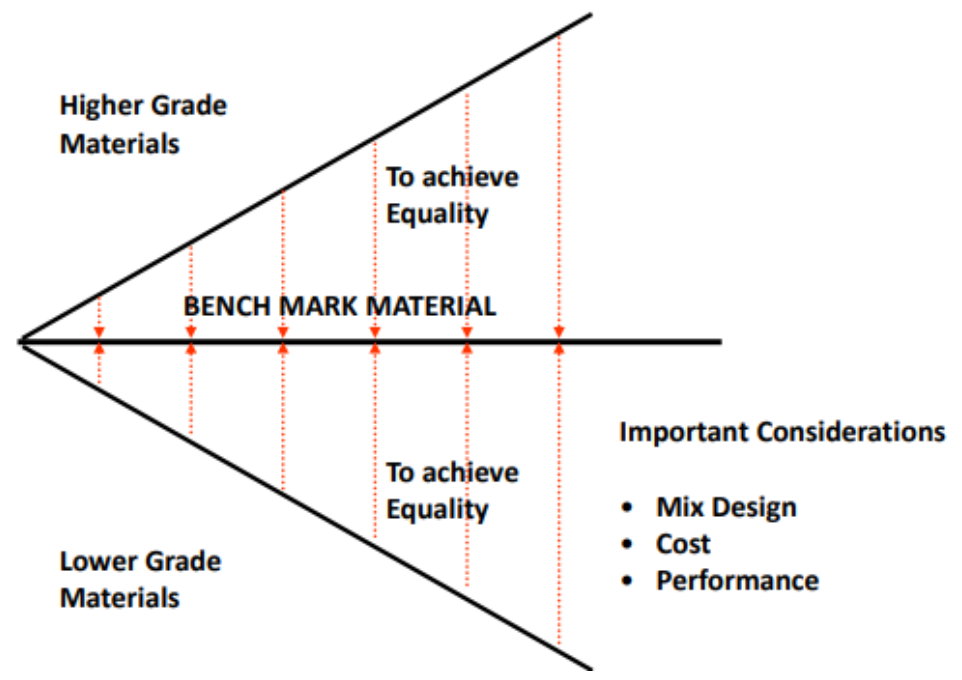

Figure 6. Benchmark materials towards a sustainable construction practice $[34,47,48]$. 
The aim of sustainability of vital resources is to create and safeguard natural resources like beaches, reserves, and islands. Additionally, it aims to establish optimum environments to appeal to the private industry and catalyze its roles to recover and sustain these natural resources [29]. Furthermore, sustainability of vital resources aims to enhance the ecological protection of South East Asian countries from natural dangers through vegetation to both safeguard against pests and combat desertification [49]. Moreover, vital resources sustainability aims to enhance the national capability to forecast natural threats and minimize the time of responses to safeguard environmental, human, and economic impacts. Further, it intends to create biological resources of South East Asian countries and ensure their sustainability via concentrating on labor availability, drug and food security, and water resources. This would reinforce the effective crisis management national capabilities [49]. The major agencies involved in sustainability of vital resources include the Social and Labor Development Ministry, Health Ministry, Planning and Economy Ministry, Authority of Saudi Wildlife, Environmental Protection and Meteorology General Authority, Corporation of Saline Water Conversions, and Agriculture, Environment, and Water Ministry.

The challenges facing sustainability of vital resources are overcome via various strategic goals [29]. Some of the strategic objectives include ensuring sustainable access to water resources, ensuring food security and developments, protecting and rehabilitating the natural landscape, and providing ecological protection from natural threats. Environmental protection prevents natural hazards like epidemics, sandstorms, floods, and desertification [49]. Protection and rehabilitation of natural landscapes establish reserved areas like islands, natural reserves, and beaches with building codes and land ownership. They also impose restrictions to specific practices such as vandalism, dumping, fishing, and animal hunting [49]. Additionally, protection and rehabilitation of natural landscapes facilitates the access to certain locations without posing dangers to the rehabilitation of the affected natural areas and the ecological sustainability.

\section{Industry and Governmental Initiatives}

For better economic growth, new constructions are needed [49]. Reclaimed concrete aggregates reduce the need for harvesting, cultivating, or mining different materials utilized in building and constructions. The reduced production and manufacturing of cements as well have notable economic benefits. Recycled concretes are obtained from processed aggregate debris from demolition wastes, giving the RCA new life in a broad range of applications [50]. Recycled concretes minimize the need for material mining. Using heavy machines, these resources must be excavated. The process of mining the materials is incredibly expensive and generates many hazardous waste substances. However, utilizing existing reclaimed concrete aggregates largely eliminates the excavation necessity as a method of obtaining the chief materials used in construction. The application of these reclaimed concretes includes being broken up into ripraps for standard construction, uses in landscaping and marine structures, and securing shorelines. Recycled concretes save on transporting natural concretes [51]. Most mined concretes have to be transported or shipped to concrete mixing centers for production.

The industrial implementation of RCA in South East Asia is still in its infancy, although there is a substantial research body associated with utilizing RCA in the generation of concrete mixes [52]. The governmental agencies initiate some of the implementations and the industry carry out some other implementations. The governments in South East Asia have acknowledged the challenges posed by the construction demolition wastes [53]. With daily capacity of about 5-25 thousand tons of construction wastes, the Malaysian government approved the Environment Protection Industrial Co (EPIC) to begin construction waste recycling plants to minimize the areas needed for landfills. In 2005, the Malaysia International Industrial projects corporation was started with the goal of enhancing the ecological conditions in Malaysia [49]. Minimizing the landfill space needs and cutting the new concrete production costs are some of the projects for this corporation. Old asphalt concretes and concrete rubbles are crushed to different sizes to be utilized as aggregates 
for some projects for this purpose [53]. The generated aggregates can be utilized in various projects, such as ordinary non-reinforced concrete mixes, asphalt concrete mixes for road paving, base and sub-base layers for road constructions, and packaging of rain and drainage pipes.

Efforts toward utilizing waste concretes and recycled aggregates are underway in the process of generating sustainable concretes in Indonesia [54]. The application of crushed recycled concretes to non-structural uses such as blinding slabs, backfills, embankments, core fillings, and road base or subbase constructions are some of the potential implementations and benefits of recycled aggregates and waste concretes [55]. Establishment of the Indonesia Green Building Council, which is a private agency interested in the promotion of ecologically sustainable practices, is another effort to assist Indonesia in adopting green building designs and constructions. Indonesia Green Building Council is implementing environment management systems that allow the companies to recycle concretes and water and use waste management programs [56]. Domestic solid waste management centers that the Ministry of Agriculture and Affairs initiated in Indonesia are able to recycle a total of 6000 tons of construction wastes and a total of 2500 tons of mixed local wastes daily.

The Riyadh Exhibitions Company Limited has been organizing waste management and global recycling to help the corporations to interact with and foster waste recycling. In Singapore, recycling plants have sorted capacities of up to 1500 tons/day [57]. However, the plants do not recycle any building materials. The restricted implementations of recycled concretes in constructions in Singapore have provoked some engineers and experts to appeal to municipalities in Singapore and other towns to introduce recycling plants and to call for strong rules to safeguard mountains from crushers in Singapore.

In the South East Asian region, Thailand appears to be one of the most active nations when it comes to the concrete recycling applications [33]. Thailand Central Lab has signed agreements with a city municipality named Tesaban Nakhon (TN) and Thailand Recycling to research and analyze building demolition wastes. The projects aim at finding meaningful applications to utilize construction rubbles, since these wastes are often ignored by contractors [58]. In city municipality $\mathrm{TN}$, the municipality has supported multiple schemes concerning ecologically friendly building materials and green building. For instance, new crushing plants in town municipality TN have been newly launched with the ability to crush waste materials and turn them into aggregates that can be utilized to substitute virgin aggregates in producing concretes. There are various companies in a sub-district municipality TN that support green concrete production. In the municipality, the companies utilize over two tons of recycled aggregates of needed concretes [59]. By utilizing recycled aggregates and other reclaimed waste materials, these companies have the ability to generate concretes that are ecologically friendly, aiming to maximize waste material usage and zero waste production.

Additionally, the Sharjah Emirate has its share of tasks in the field of sustainable construction. New recycling plants recently were established in the Sharjah's industrial areas [60]. The plants receive concretes and other building waste materials for different regions within the Emirate and process them to be utilized again for building activities. The concrete applications are scarce in the Philippines [61]. Nevertheless, in 2009, the royal decrees have been issued to appoint the Philippine Ecological Services Holding Corporation to implement the tasks of executing the state policies regarding the waste industry. The company has initiated several schemes to develop facilities for management of tire recycling plants, electronic wastes, hazardous wastes, and medical wastes in addition to the management of landfills all over the Philippines [62]. In the Philippines, the production of about 3000 tons of wastes every day has inspired the initiatives to plan for reclaiming factories that will recycle the majority of those wastes.

\section{Restructuring the Public and Private Sectors to the Utilization of RCA}

Stakeholders appropriate to RCA utilization, including the general public, transportation firms, construction waste disposal organizations, construction firms, local govern- 
ments, developers, and central government agencies, should work together to realize the full potential of RCAs [63]. This work suggests that there should be recommendations to foster the recycling of construction and demolition wastes and utilization of RCA, applications and prices of construction and demolition recycled materials such as RCA, RCA promotion, and construction and demolition recycling awareness. Including sector and information technology and finance, environmental protections, transport, municipal administration and landscapes, planning, housing and construction, land resources, development, and reform commission, the RCA management of local governments involves various departments of government administration with their respective management responsibilities and privileges [63]. In most cases, the urban administration department of China is the main construction and demolition waste agency. The issues are similar to those at national level at the local government level.

Generally, the stakeholders believe that RCAs are odorless, inert, and non-toxic materials [62]. There are minimal complaints about the RCAs. Public safety impacts are not considered, and the resource and environmental conservation awareness is weak. The government solid waste declarations and the Building Law for instance do not consider RCA at all. There is no provision for construction demolitions. While demolition is overlooked, the management and administration only care about constructions [29]. The stakeholders should therefore work together to realize the applications of RCAs. They should come up with unified calculation standards and RCA production statistical systems. The private and public sector should work together to develop regulations that outline quantitative targets for requirements and standards of RCA pollution control, disposal and recycling, and RCA generation that bring hurdles in the real management of RCA. Basically, the public and private sectors have to work to ensure that the mode of RCA generation follows an open and planned economy. The RCA administrative department should shoulder the law enforcement and supervision activities and bear the qualification approval responsibilities [30]. The cooperation between the public and private sectors integrates enforcement and administration and strengthens the efficiency of macro-management functions, which will seriously improve RCA utilization.

The government, design institutes, construction units, and project managers should be involved in generation and utilization of RCA [31]. During the demolition and construction, the project owners are the major players. The project owners are in the center at the source generation stage. While achieving work that adheres with standards and principles, meeting the project owner requirements, and completing as many projects in the shortest time possible, the main concerns of design include integrating the ideas into the buildings and structures. The construction departments are interested in how to finish the constructions with the least cost inputs and resources and the fastest rates. The government should support more generation and utilization of RCAs [9]. Their obligations, expectations, and responsibilities must be properly coordinated.

\section{Maintaining Stability and Sustaining Growth of RCA}

Lots of construction tasks are seen everywhere with the modernization and development of societies [29]. The construction tasks are growing by huge amounts and at faster rates. The destructions of existing buildings and structures that have attained their service lives also run parallel to activities of construction. It is necessary that the buildings should be destroyed and smashed because of ongoing reconstruction trends and change in fashion as well as when they have completed their service lives [32]. South East Asian countries are looking for healthy buildings to create more spaces to meet the current demands. The construction activities as such are producing waste materials in bulk. These wastes are known as demolition and construction wastes [38]. For the owners, builders, developers, and engineers, the disposal of such demolition and construction wastes in a sustainable way is a challenging activity [35]. On the other hand, there are grave shortages of virginally available concretes and aggregates for the building of structures, while the disposal of construction and demolition wastes is a challenge. Reductions of these demands in small 
ways are possible with reusing and reclaiming of demolition and construction wastes produced from construction activities [39]. Therefore, the reclamation of demolished wastes is a sustainable solution to demolition and construction wastes.

Natural resources are scarce in nature [39]. With time, the natural resources will be depleted. Unnecessary wasting of natural resources should be regulated and limited to conserve natural resources. Throughout the projects' life cycle, formulations and implementations of the proper waste management plan can reduce construction and demolition wastes. Most of the construction and demolition wastes can be reclaimed and reused with incorporated resource management schemes, and more virgin concrete can be conserved for our future generations [41]. In addition to judicial laws from the concerned regulatory agencies and bodies, the recycling successes require promotion by means of information and education.

Strong commitments and investments by private bodies and state agencies are essential to ensure sustainability. Some materials such as glasses and plastics are reused for recycling. Concretes can also be utilized continually in the same manner as long as the specifications are correct [32]. For construction purposes, recycling solid waste products is gradually becoming an important construction and demolition waste management alternative because it overcome the obstacles such as environmental regulations, more restrictive land use, and depletions of natural concrete reserves. The presence of inert material (such as grit from road sweeping, dusts, and drain silts) and demolition and construction wastes is important [29]. About $33 \%$ of total municipal solid wastes are generated from construction and demolition wastes. Recycling of demolition and construction wastes should be focused on in view of:

- The potential to save virgin concretes and aggregates such as soils, stones, and river sands.

- Their bulk that is carried over longer distances just for disposing.

- They are occupying significant spaces at sites of landfills.

- Their presence is spoiling the processing of recyclable and bio-degradable wastes.

Demolition and construction wastes have potential applications after grading and processing [30]. Applications of demolition and construction wastes are quite common in developed economies. The various state agencies and private bodies responsible for the production of waste substances and materials need to separate the produced waste products with potential for recycling or reuse in the future [31]. The engineers in charge should ensure proper treatment of waste products generated from such developments, utilize reclaimed concretes, and choose the materials and types of structures that are appropriate for recycling and reuse. From building and construction, the generation of wastes needs to be reduced [9]. The waste generation should also reduce the hazardous effects from the generated waste materials.

In these processes of demolition and construction wastes' reuse and recycling, different sub-contractors, agencies, and bodies to be engaged are to be linked up in the steps [32]. The few steps include the collection and transportation of wastes, treatment of intermediate wastes, which is receiving the wastes, their segregations, and further appropriate extensive treatments before putting them into the applications [38]. There may be compliant contractors, or there may be important roles to assign. They need to create step-by-step demolition programs and processes. At the beginning of the constructions, different sub-contractors, agencies, and bodies need to report anticipated quantities of waste materials by types and treatment plans. There is need for safe treatments of hazardous wastes such as asbestos and effective use of reclaimed aggregate concretes [35]. During construction, the contractors can be requested to submit an environmental management program.

To improve the rates of applications of demolished concretes for applications of reclaimed aggregates, all information about construction and demolition wastes from those involved in the process such as contractors and waste treatment firms should be submitted in public domains [39]. This helps in reducing the quantities of waste materials and promoting the reuse or recycling of the construction and demolition wastes. There should 
also be a demolition plan. While demolishing structures and buildings, demolition plans are needed to embrace systematic approaches to reducing wastes. A demolition plan ensures the best application of construction and demolition wastes. A proposed strategy may be to follow a series of household waste segregations as an initial stage, followed by roof finishing, water-proof materials, exterior and interior finishing materials, and electrical and mechanical equipment, and then the structures as last resorts [41]. Demolished debris should be temporarily stored in designated areas for the demolition and construction wastes or removed from the field immediately.

\section{Developing Cooperation, Establishment of New Structures, and Improving Capacities}

Developing cooperation, establishment of new structures, and improving capacities are approaches to establishing and promoting the development of sustainable, durable, cost-effective, green concrete by utilizing recycled aggregates [29]. Additionally, the environmental conservation agencies and authorities in different countries in the region should network with other Asian environmental conservation bodies by establishing platforms for collective responses to support the organized and transnational development of sustainable, durable, cost-effective, green concrete by utilizing recycled aggregates [30]. They should set collective proactive methods to strengthen the links and accentuate coordination at national, regional, and international levels for the development of sustainable, durable, cost-effective, green concrete by utilizing recycled aggregates. The coordinated and collective responses consist of project activities to reduce construction wastes [31]. The overall collaboration program can help foster regional and global cooperation in Asia, establish technical infrastructures, strengthen institutional capacities, and implement national strategies for the development of sustainable, durable, cost-effective, green concrete by utilizing recycled aggregates.

The development and establishment of national structures supporting the development of sustainable, durable, cost-effective, green concrete by utilizing recycled aggregates can be reinforced through the execution of three programs, including strengthening the capacity of waste services and other waste management bodies and strengthening the State Services on Waste Control of different states in South East Asia and the Asia Waste Control Agency in implementing trade and border control, specifically import and export regimes [9]. Specifically, these programs aim to support the legal frameworks to support the development of sustainable, durable, cost-effective, green concrete through the utilization of recycled aggregates, coordination and mobilization of recycling activities, and effective monitoring of waste situations in these countries. The frameworks of the development efforts of sustainable, durable, cost-effective, green concrete by utilizing recycled aggregates envisage global cooperation improvements by strengthening the existing initiatives of strengthening national cooperation and improving joint operational activities [41]. The programs aim to design national law enforcement capacities to support the development of sustainable, durable, cost-effective, green concrete by utilizing recycled aggregates.

Information sharing, analytical capacity building, and coordination in regional operations are supported via two programs, including strengthening waste management law enforcement systems for waste management exchanges, collections, and analyses and establishing the Asian Coordination Center and Regional Information [32]. The establishment of the Asian Coordination Center and Regional Information aims to help waste management and recycling agencies in South East Asia by offering operational and technical waste management training analysts through creating ways to establish databases and information sharing and deliver waste management systems [38]. Strengthening waste management enforcement systems for information exchanges, collections, and analyses particularly reinforce waste prevention and purposes to establish regional collaborations, coordination, and information sharing among the waste management and recycling institutions of the member countries. The international waste management and control program implements activities in construction and building waste management [35]. The demolition waste programs help the governments establish sustainable construction waste management 
systems for the development of sustainable, durable, cost-effective, green concrete by utilizing recycled aggregates.

To coordinate diverse sub-regional stakeholders, identifiable and strong supranational leadership and leaders are essential given the different components of the effective development of sustainable, durable, cost-effective, green concrete by utilizing recycled aggregates approaches and robust reporting promotion [30]. The General Construction and Building Waste Management Authority is a national body that undertakes governance roles. The General Construction and Building Waste Management Authority leadership needs to determine requirements and problems for effective construction waste management strategies. The General Construction and Building Waste Management Authority leadership makes policy suggestions to ensure the concretes available to the public are safe [31]. The General Construction and Building Waste Management Authority leadership should develop tools to detect, prevent, and control construction waste. The General Construction and Building Waste Management Authority should strengthen regional and national capacity for the integrity of supply chains of recycled concretes. The body should promote cooperation, collaboration, and consultation among crucial agencies that include partnerships with other waste management officials and institutions outside South East Asia. The General Customs Authority should also encourage information sharing [29]. The agency should strengthen quality control regulatory capacity at regional and national levels.

The South East Asian government should fund the development of sustainable, durable, cost-effective, green concrete by utilizing recycled aggregates plans and programs to promote the spread of applications of recycled concrete aggregates [9]. To secure time, personnel, and cash at the global level, construction waste as a public health problem needs to be raised on the international agenda. For example, the current investments in reducing construction wastes should be matched with proper control and monitoring [32]. Given the global trade and international laws, construction and building waste needs to be on radars. Similar global attention is required on transnational promotion of recycled concrete aggregates. From the factories generating recycled concrete aggregates to vendors selling the concretes and aggregate, the concrete chains consist of a long distribution chain [38]. The supply chain internationalization leads to significant complexities, offering multiple entry points for poor quality concretes. Even nations such as Singapore and Malaysia, with strict monitoring of the distribution and sales of cement and other concretes, have had their efforts compromised by markets of poor-quality cements in the bordering states [41]. Having tight state controls over the cement supply chains is one approach to keep South East Asia from accessing poor quality building and construction materials.

In the development of sustainable, durable, cost-effective, green concrete by utilizing recycled aggregates, success requires global, interlocking national and regional strategies based on international cooperation [41]. South East Asian authorities and officers should adopt comprehensive approaches and strategies to promote the development of sustainable, durable, cost-effective, green concrete by utilizing recycled aggregates. The development of sustainable, durable, cost-effective, green concrete by utilizing recycled aggregates needs to be supported on multiple fronts in a synchronized manner [32]. The development of sustainable, durable, cost-effective, green concrete by utilizing recycled aggregates efforts need to be intensified. Alternative development programs should be sufficiently expansive in scope and adequately funded to ensure their sustainability. Many of the achievements will be due to deliberate steps taken to strengthen both the infrastructures and waste management eradication efforts [35]. In the coming months, South Asian governments should focus on offering alternative substitution concretes to ensure that their progress toward construction and building waste-free environments is sustainable.

In the recent past, the parts played by research in evaluating and designing rules that govern the development of sustainable, durable, cost-effective, green concrete by utilizing recycled aggregates have become very important [29]. Research can carry out two primary functions. Firstly, fundamental knowledge from science helps in identifying risk elements 
linked with the recycling construction wastes. Ascertaining risk elements is paramount in designing programs for intervention and prevention of construction and building wastes. Secondly, the researchers' role is that which has been termed the "method of solving the problem" [30]. This method has an origin that can be traced back to the commonly known "Boston Project" that required the involvement of an agency carrying out research and independent bodies as a critical party in the designing, implementation, and continuing assessment of inventiveness. Convening for meetings that will enlighten the possible development of sustainable, durable, cost-effective, green concrete by utilizing recycled aggregates is very important in managing and controlling the production of recycled concrete aggregates [31]. They have to know that communities will not endure wastes that involve construction and building. The information should be passed on frequently and directly.

The environmental compliance should be raised from $37 \%$ to $70 \%$, and the pollution of the environment caused by human and industrial activities has to be reduced [31]. The ecological inspection must be expanded and controlled to strengthen the monitoring of sustainable environmental practice. This can be made possible by establishing a specialized center. The polluted areas can be reduced by rehabilitating them by controlling and managing those areas. The management of the chemical substances and wastes should be strengthened to ensure that no chemical residues are disposed of in the environment where they can be harmful to the health of the residents [9]. The National Program for Chemical safety and Hazardous Waste Management must be activated to monitor the disposal of such chemical wastes and substances to the right place where they will not affect the health of the city's residents.

This aims at developing and protecting the natural areas like islands, beaches, and reserves [31]. It also aims at formulating an optimum environment to attract private sectors and make them active in rehabilitating and maintaining those natural areas. It also seeks to improve at protecting the Kingdom's atmosphere from natural disasters through vegetation to combat desertification and protect from pests and insects [9]. The national capability to predict the natural hazards will be improved to ensure protection against economic, human, and environmental effects. It also intends to develop of the biological resources in the Kingdom to enhance sustainability by focusing on food security, labor availability, and water resources. This will help the nation to strengthen its capacity to manage the crisis effectively [9]. Some of the ministries involved in ensuring the sustainability of vital resources include the Ministry of Environment, Water and Agriculture, authorities in charge of wildlife, Health Ministry, and the Labor Ministry just to mention a few. The government aims to achieve an integrated management of both renewable and nonrenewable water resources for sustainable use in the privatization of RCA production. They aim at affecting the use of the available building and construction resources and maximizing the use of recycled concretes [9]. This should develop the supply of building and construction resources.

\section{Best Practices and Strategies}

The urban landscape in South East Asia should be improved by enlightening the public and community spaces where people can relax on green grass [9]. Visual pollution should also be reduced such as landfills and the construction areas. Comprehensive urban planning should be implemented to ensure the achievement of sustainable development through city planning, management, and data-based integration. Effective urban design standards and controls have to be developed to improve the urban environment in the city centers. A sustainable, healthy environment has to be provided through the development of the municipal control, management of wastes, and environmental sanitation [49]. Land management and protection should be developed by the inventory and documentation of the land and the real estate companies.

There are no stable sources of materials for construction waste recycling firms because of the absence of measures for transportation and mandatory dumping of construction 
wastes according to the study, leading to the revenue stability absence for factories involved in production and also having certain effects on the market sustainability, for instance, fixed construction waste recycling [9]. In the market, the sales price is not a hindrance affecting market applications of RCA, since there are scenarios in which their costs are lesser than products of common construction materials. It is more a market acceptance factor of recycled concrete aggregates [49]. In the sector, the absence of accreditation identification systems and uniform quality certification and their narrow applications cause some marketing problems.

A variety of transformative programs are put in place to ensure the realization of sustainable production of RCA [49]. First, South East Asian countries should restructure their governments by organizing the various governmental practices through the prioritization of activities. As the vision realization process remains a regular practice through the achievement of objectives throughout the period, the most urgent needs should be satisfied within the given duration. To enhance the successful accomplishment of each program, the governments need to have a strategy to manage each project with its resources [9]. The management at each level in every program remains questionable for every action or failure. Co-ordination within each project remains an essential aspect of ensuring that all efforts are gathered and maximally utilized to attain the desired goals. A central delivery unit to oversee the entire project provides that all the stakeholders remain active in their responsibilities [31]. As sometimes the vision achievement process utilizes the trial and error method, bodies reformulating the existing laws to fix the ones that align with the goals remain essential in the long run.

After everything is in place, a system to ensure that the instituted programs perform as intended through a performance review program becomes essential [9]. The South East Asian governments enhanced this practice by developing a committee to oversee and assess the performance of the various sectors in productions of RCA. The program analyzes all categories of the distinct segments within and without the governments. Such criteria create conviction for the stakeholders that they have the sole mandate to perform [31]. The regulatory measures prevent misappropriation of funds by imposing the liability on the various personnel, and everyone involved is prone to punishment according to the existing law.

Implementation of the Experience Strategic Partnerships Program would become successful from the various supportive responses from the different nations in the world [31]. For instance, the United Kingdom proposed total support for the partnership program with Saudi Arabia. The U.K. support of pioneering investment powers strategic partnerships with Middle Eastern countries including Saudi Arabia [49]. The Kingdom also proposes to act as a center of dialogue to the world on deliberations to partner with Saudi Arabia for the realization of production of RCA. A friendly foreign-investment environment has been set out in the South East Asian territories. Security improvement as well as infrastructure, especially in the major cities and towns, provides limelight on the great achievement of the program implementation [9]. The technological developments resulting from the partnership program have become facilitated by the concentration and restructuring of the energy system and the telecommunication networks in South East Asian territories.

The increase in the standard of relationship is perceived as an avenue to elevate the level of investment observed in the region [9]. South East Asian countries experience Foreign Direct Investment (FDI), which has also resulted in a downward drift in the production of RCA of the countries. Several ministries and authorities cited the need to cooperate in the project of elevating the services. The elevation depends on the efforts to advance the production of RCA. The partnership between the sectors is perceived as the avenue to generate significant recycled concrete aggregates [31]. The increase rests on the improvement of infrastructure, significantly of the services availed in the transport sectors.

The capacity to transform the strategic production of RCA in South East Asia into an international producer is to relate with other continents [9]. South East Asian countries should try to use the collaboration as a technique to heighten the multilateral relationship, 
such as the interaction with Australia, which observes an enjoyable relationship [31]. The two regions have strong interactions, which rest on the need to provide policies to foster the ideologies of RCA production in the region. Furthermore, the people in the countries should interact through education, which binds them together in institutions and trading avenues. The relationship provides an opportunity to improve RCA production of all states, since all the states practice aspects such as mining services, agriculture, education, and construction. Therefore, the interactions employed by South East Asian countries focus on the development of the countries and the attainment of RCA production goals [49]. The perceived relations affect the countries' growth, promote the advancement of RCA production, and increase recognition of South East Asian countries, placing them on the list of the top-ranked 100 countries in production of RCA in the world.

\section{Needful Investigations for Future Research}

It is assumed that most of the deformation by creep is caused by the deformation of the cement paste [64]. However, it was also found that the porosity of aggregates affects the modulus of elasticity and thus indirectly affects concrete creep [65]. Studies on the effect of using different types of NA on the creep behaviour of concrete showed significant difference in creep strain [52]. As the aggregates' elastic moduli decrease, which is the case in RA, there is a greater stress on the cement paste and thus greater creep. For this reason, it is vital that the quality of RA is evaluated in order to understand their role in the creep behaviour of concrete. As previously mentioned, in the authors' previous study [66], they proposed a performance-based classification as a means to measure the quality of RA. Later on, this knowledge was used to establish a relationship between the modulus of elasticity and compressive strength of RAC [67] according to the EC2 [68]. It was found that as the RA content increased, the moduli of elasticity decreased, and more so with decreasing RA quality. By means of a statistical analysis, they also found that, for the same compressive strength, RAC exhibited a maximum loss in elastic moduli similar to that of concrete with sandstone. Considering the above information and given the scarcity of data on the effect of RA on creep of concrete, it is suggested that further research is undertaken on this matter. In future laboratory trials, instead of using RA without criteria, researchers should measure the quality of RA, prior to concrete production, according to the performance-based classification of RA [66]. This classification, apart from providing an easy-to-use method for categorising RA by operatives in CDW recycling facilities and ready-mixed concrete plants, has allowed predicting the mechanical behaviour of $\operatorname{RAC}[67,69]$.

In conclusion, we would like to point out that mining is growing around the world, causing serious social and environmental consequences and, thus, causing significant resistance. Bisht and Gerber [70] provided the overview of non-fuel mining conflicts in India. The analysis is based on 100 cases of conflict that occurred between 1992 and 2014. In each case, the location, mining operations, actors involved, reasons for the protest, duration of the conflict, and results were recorded. The commodity causing most conflicts is sand, which is widely mined and often carried out by illegal actors near rivers. In contrast, resistance to metal mining tends to turn the local population against larger corporations. Most resistance movements are composed of the lower strata of the rural and/or indigenous population. The causes of such conflicts are largely environmental and lead to the undermining of the livelihoods of local populations. India's mining operations are expected to increase over the next decade, and with it the number of related conflicts. Based on the above, the recycling of aggregate is essential.

\section{Conclusions}

In conclusion, several policy recommendations and analyses are available. The policies concerning the development of sustainable, durable, cost-effective, green concrete by utilizing recycled aggregates provide exclusive challenges and opportunities in South East Asia. On a constructive side of dealing with the issue in question, the rules provided by 
South East Asian governments concerning the development of sustainable, durable, costeffective, green concrete by utilizing recycled aggregates issues are supposed to offer many other chances for studying the consequences and promotion of recycled concrete markets. Much should be learned regarding the activities and operations of the construction and building wastes for effective and successful intervention strategies of the development of sustainable, durable, cost-effective, green concrete by utilizing recycled aggregates.

Author Contributions: N.M. and R.F.; data curation, M.A., A.M.Z., S.K., R.F., N.V. and M.K.; formal analysis, R.F., M.A. and A.R.G.d.A.; funding acquisition, M.A., R.F., N.V. and M.K.; investigation, N.M., A.R.G.d.A., M.A. and M.K.; methodology, N.M., M.A. and A.M.Z.; project administration, M.A., R.F., N.V. and M.K.; resources, M.A., M.K., A.R.G.d.A., R.F., N.V. and N.M.; software, S.K. and R.F.; supervision, N.M. and R.F.; validation, M.A., N.V. and A.R.G.d.A.; visualization, N.M. and R.F.; writing-original draft, M.A., A.M.Z., S.K., R.F., N.V. and M.K. All authors have read and agreed to the published version of the manuscript.

Funding: The research was supported by the Ministry of Science and Education of the Russian Federation in accordance with the decision of the Council for Grants of the Government of the Russian Federation for state support of scientific research conducted under the guidance of leading scientists in Russian educational institutions of higher education, scientific institutions, and state scientific centers of the Russian Federation, dated 11 January 2021, application No. 2020-220-08-6558.

Institutional Review Board Statement: Not applicable.

Informed Consent Statement: Not applicable.

Data Availability Statement: Data sharing not applicable.

Conflicts of Interest: The authors declare no conflict of interest.

\section{References}

1. Varshney, H.; Khan, R.A.; Khan, I.K. Sustainable use of different wastewater in concrete construction: A review. J. Build. Eng. 2021, 41, 102411. [CrossRef]

2. Galetakis, M.; Soultana, A. A review on the utilisation of quarry and ornamental stone industry fine by-products in the construction sector. Constr. Build. Mater. 2016, 102, 769-781. [CrossRef]

3. Salman Rais, M.; Ahmad Khan, R. Effect of biomineralization technique on the strength and durability characteristics of recycled aggregate concrete. Constr. Build. Mater. 2021, 290, 123280. [CrossRef]

4. Hamada, H.M.; Thomas, B.S.; Yahaya, F.M.; Muthusamy, K.; Yang, J.; Abdalla, J.A.; Hawileh, R.A. Sustainable use of palm oil fuel ash as a supplementary cementitious material: A comprehensive review. J. Build. Eng. 2021, 40, 102286. [CrossRef]

5. Miranda de Souza, A.; Soares de Lima, G.E.; Nalon, G.H.; Salgado Lopes, M.M.; Luis de Oliviera Júnior, A.; Rodrigues Lopes, G.J.; José de Andrade Olivier, M.; Pedroti, L.G.; Lopes Ribeiro, J.C.; Franco de Carvalho, J.M. Application of the desirability function for the development of new composite eco-efficiency indicators for concrete. J. Build. Eng. 2021, 40, 102374. [CrossRef]

6. Hoang, N.H.; Ishigaki, T.; Kubota, R.; Yamada, M.; Kawamoto, K. A review of construction and demolition waste management in Southeast Asia. J. Mater. Cycles Waste Manag. 2020, 22, 315-325. [CrossRef]

7. Shatkin, G. The real estate turn in policy and planning: Land monetization and the political economy of peri-urbanization in Asia. Cities 2016, 53, 141-149. [CrossRef]

8. Prema-chandra, A.; Waglé, S. Foreign Direct Investment in Southeast Asia-Is Malaysia Falling Behind? Asean Econ. Bull. 2011, 28, 115. [CrossRef]

9. Busari, A.; Adeyanju, E.; Loto, T.; Ademola, D. Recycled Aggregate in Pavement Construction: Review of Literatures. In Proceedings of the Journal of Physics: Conference Series; IOP Publishing: Bristol, UK, 2019; Volume 1378.

10. Feduik, R. Reducing permeability of fiber concrete using composite binders. Spéc. Top. Rev. Porous Media Int. J. 2018, 9, 79-89. [CrossRef]

11. Ayzenshtadt, A.; Lesovik, V.; Frolova, M.; Tutygin, A.; Danilov, V. Nanostructured Wood Mineral Composite. Procedia Eng. 2015, 117, 45-51. [CrossRef]

12. Kozhuhova, N.; Strokova, V.; Kozhuhova, M.; Zhernovskiy, I. Structure formation in alkali activated aluminosilicate binding systems using natural raw materials with different crystallinity degree. Constr. Mater. Prod. 2020, 1, 38-43. [CrossRef]

13. Ferreira, R.L.S.; Anjos, H.M.M.A.S.; Maia, C.; Pinto, L.; de Azevedo, A.R.G.; de Brito, J. Long-term analysis of the physical properties of the mixed recycled aggregate and their effect on the properties of mortars. Constr. Build. Mater. 2021, $274,121796$. [CrossRef]

14. Mendes, B.C.; Pedroti, L.G.; Fontes, M.; Ribeiro, J.C.L.; Vieira, C.M.; Pacheco, A.A.; de Azevedo, A.R.G. Technical and environmental assessment of the incorporation of iron ore tailings in construction clay bricks. Constr. Build. Mater. 2019, 227, 116669. [CrossRef] 
15. Tam, V.W.-Y.; Lu, W. Construction Waste Management Profiles, Practices, and Performance: A Cross-Jurisdictional Analysis in Four Countries. Sustainability 2016, 8, 190. [CrossRef]

16. Chernysheva, N.V.; Lesovik, V.S.; Drebezgova, M.Y.; Shatalova, S.V.; Alaskhanov, A.H. Composite Gypsum Binders with Silicacontaining Additives. In Proceedings of the IOP Conference Series: Materials Science and Engineering; IOP Publishing: Bristol, UK, 2018; Volume 327, p. 032015.

17. Fediuk, R.; Pak, A.; Kuzmin, D. Fine-Grained Concrete of Composite Binder. In Proceedings of the IOP Conference Series: Materials Science and Engineering; IOP Publishing: Bristol, UK, 2017; Volume 262, p. 012025.

18. Nunez, I.; Nehdi, M.L. Machine learning prediction of carbonation depth in recycled aggregate concrete incorporating SCMs. Constr. Build. Mater. 2021, 287, 123027. [CrossRef]

19. Marvila, M.T.; Azevedo, A.R.; Barroso, L.S.; Barbosa, M.Z.; de Brito, J. Gypsum plaster using rock waste: A proposal to repair the renderings of historical buildings in Brazil. Constr. Build. Mater. 2020, 250, 118786. [CrossRef]

20. Santhosh, K.G.; Subhani, S.M.; Bahurudeen, A. Cleaner production of concrete by using industrial by-products as fine aggregate: A sustainable solution to excessive river sand mining. J. Build. Eng. 2021, 42, 102415. [CrossRef]

21. Ogata, Y.; Ishigaki, T.; Ebie, Y.; Sutthasil, N.; Chiemchaisri, C.; Yamada, M. Effect of feed pattern of landfill leachate on water reduction in constructed wetland in Southeast Asia. Water Pract. Technol. 2015, 10, 669-673. [CrossRef]

22. Xue, W.; Cao, K.; Li, W. Municipal solid waste collection optimization in Singapore. Appl. Geogr. 2015, 62, 182-190. [CrossRef]

23. Li, J.; Liang, J.; Zuo, J.; Guo, H. Environmental impact assessment of mobile recycling of demolition waste in Shenzhen, China. J. Clean. Prod. 2020, 263, 121371. [CrossRef]

24. Makul, N.; Fediuk, R.; Amran, M.; Zeyad, A.; Murali, G.; Vatin, N.; Klyuev, S.; Ozbakkaloglu, T.; Vasilev, Y. Use of Recycled Concrete Aggregates in Production of Green Cement-Based Concrete Composites: A Review. Crystallography 2021, 11, 232. [CrossRef]

25. Chen, Y.; Chen, Z.; Xu, J.; Lui, E.M.; Wu, B. Performance evaluation of recycled aggregate concrete under multiaxial compression. Constr. Build. Mater. 2019, 229, 116935. [CrossRef]

26. Akbarnezhad, A.; Xiao, J. Estimation and Minimization of Embodied Carbon of Buildings: A Review. Buildings 2017, 7, 5. [CrossRef]

27. Fediuk, R.; Yushin, A. Composite binders for concrete with reduced permeability. In Proceedings of the IOP Conference Series: Materials Science and Engineering; IOP Publishing: Bristol, UK, 2016; Volume 116, p. 012021.

28. Fediuk, R.S.; A Ibragimov, R.; Lesovik, V.S.; A Pak, A.; Krylov, V.V.; Poleschuk, M.M.; Stoyushko, N.Y.; A Gladkova, N. Processing equipment for grinding of building powders. In Proceedings of the IOP Conference Series: Materials Science and Engineering; IOP Publishing: Bristol, UK, 2018; Volume 327.

29. Ajdukiewicz, A.B.; Kliszczewicz, A.T. Comparative Tests of Beams and Columns Made of Recycled Aggregate Concrete and Natural Aggregate Concrete. J. Adv. Concr. Technol. 2007, 5, 259-273. [CrossRef]

30. Akhtar, A.; Sarmah, A.K. Construction and demolition waste generation and properties of recycled aggregate concrete: A global perspective. J. Clean. Prod. 2018, 186, 262-281. [CrossRef]

31. Behera, M.; Bhattacharyya, S.; Minocha, A.; Deoliya, R.; Maiti, S. Recycled aggregate from C\&D waste \& its use in concrete - A breakthrough towards sustainability in construction sector: A review. Constr. Build. Mater. 2014, 68, 501-516. [CrossRef]

32. Corinaldesi, V.; Moriconi, G. The use of recycled aggregates from building demolition in self-compacting concrete. In Proceedings of the 3rd International RILEM Symposium on Self-Compacting Concrete; Wallevik, O.H., Nielsson, I., Eds.; RILEM Publications: Bagneux, France, 2003; pp. 251-260.

33. Xiao, J.; Wang, C.; Ding, T.; Akbar Nezhad, A. A recycled aggregate concrete high-rise building: Structural performance and embodied carbon footprint. J. Clean. Prod. 2018, 199, 868-881. [CrossRef]

34. Ding, T.; Xiao, J.; Tam, V.W.Y. A closed-loop life cycle assessment of recycled aggregate concrete utilization in China. Waste Manag. 2016, 56, 367-375. [CrossRef]

35. Guoliang, B.A.I.; Chao, L.I.U.; Shengwei, J.I.A.; Zonggang, Q.U.A.N. Study on seismic behavior of recycled concrete frame joints under low cyclic load. In Proceedings of the 2nd International Conference on Waste Engineering and Management-ICWEM, Shanghai, China, 13 October 2010; pp. 638-644.

36. Lesovik, V.S. The reducing effect of argon in the plasma treatment of high-melting nonmetallic materials (a review). Glas. Ceram. 2001, 58, 362-364.

37. Dhir Ravindra, K. Recycled Aggregates Use in Concrete Construction: The Basics; Webinar Notes; University of Birmingham: Birmingham, UK, 2021.

38. Haridharan, M.; Matheswaran, S.; Murali, G.; Abid, S.R.; Fediuk, R.; Mugahed Amran, Y.; Abdelgader, H.S. Impact response of two-layered grouted aggregate fibrous concrete composite under falling mass impact. Constr. Build. Mater. 2020, $263,120628$. [CrossRef]

39. Kulakowski, P.M.; Fedumenti, B.M.; Kazmierczak, S.C.; Mancio, M. Evaluation of chloride ion penetration methods in concrete with recycled concrete aggregate and rice husk ash. In Proceedings of the XIII International Conference on Durability of Building Materials and Components, Sao Paulo, Brazil, 2-5 September 2014.

40. Mehta, P. History and Status of Performance Tests for Evaluation of Soundness of Cements. In Cement Standards-Evolution and Trends; ASTM International: West Conshohocken, PA, USA, 1978; pp. 35-60. 
41. Klemeš, J.J.; Varbanov, P.S.; Walmsley, T.G.; Jia, X. New directions in the implementation of Pinch Methodology (PM). Renew. Sustain. Energy Rev. 2018, 98, 439-468. [CrossRef]

42. Li, L.G.; Lin, C.J.; Chen, G.M.; Kwan, A.K.H.; Jiang, T. Effects of packing on compressive behaviour of recycled aggregate concrete. Constr. Build. Mater. 2017, 157, 757-777. [CrossRef]

43. Luo, S.; Ye, S.; Xiao, J.; Zheng, J.; Zhu, Y. Carbonated recycled coarse aggregate and uniaxial compressive stress-strain relation of recycled aggregate concrete. Constr. Build. Mater. 2018, 188, 956-965. [CrossRef]

44. Millward-Hopkins, J.; Busch, J.; Purnell, P.; Zwirner, O.; Velis, C.A.; Brown, A.; Hahladakis, J.; Iacovidou, E. Fully integrated modelling for sustainability assessment of resource recovery from waste. Sci. Total Environ. 2018, 612, 613-624. [CrossRef] [PubMed]

45. Rashid, K.; Rehman, M.U.; de Brito, J.; Ghafoor, H. Multi-criteria optimization of recycled aggregate concrete mixes. J. Clean. Prod. 2020, 276, 124316. [CrossRef]

46. Mukharjee, B.B.; Barai, S.V. Influence of Nano-Silica on the properties of recycled aggregate concrete. Constr. Build. Mater. 2014, 55, 29-37. [CrossRef]

47. Chernysheva, N.; Lesovik, V.; Fediuk, R.; Vatin, N. Improvement of Performances of the Gypsum-Cement Fiber Reinforced Composite (GCFRC). Materials 2020, 13, 3847. [CrossRef]

48. Klyuyev, S.V.; Guryanov, Y.V. External reinforcing of fiber concrete constructions by carbon fiber tapes. Mag. Civ. Eng. 2013, 36, 21-26. [CrossRef]

49. Salem, R.M.; Burdette, E.G.; Jackson, N.M. Resistance to Freezing and Thawing of Recycled Aggregate Concrete. ACI Mater. J. 2003, 100. [CrossRef]

50. Shi, X.S.; Collins, F.G.; Zhao, X.L.; Wang, Q.Y. Experimental study on geopolymeric recycled concrete used as sustainable construction material. In Proceedings of the International RILEM Conference on Advances in Construction Materials through Science and Engineering; RILEM Publications: Hong Kong, China, 2011; pp. 748-755.

51. Shafii, F. Status of sustainable building in South-East Asia. In Proceedings of the Report Prepared for SB08 Melbourne, Melbourne Convention Centre, Melbourne, Australia, 21-25 September 2008.

52. Silva, R.V.; de Brito, J.; Dhir, R.K. Comparative analysis of existing prediction models on the creep behaviour of recycled aggregate concrete. Eng. Struct. 2015, 100, 31-42. [CrossRef]

53. Tam, V.W.Y.; Wang, K.; Tam, C.M. Ways to facilitate the use of recycled aggregate concrete. Proc. Inst. Civ. Eng. Waste Resour. Manag. 2007, 160, 125-129. [CrossRef]

54. Wang, J.; Xie, J.; He, J.; Sun, M.; Yang, J.; Li, L. Combined use of silica fume and steel fibre to improve fracture properties of recycled aggregate concrete exposed to elevated temperature. J. Mater. Cycles Waste Manag. 2020, 22, 862-877. [CrossRef]

55. Wang, C.; Xiao, J.; Wang, C.; Zhang, C. Nonlinear damping and nonlinear responses of recycled aggregate concrete frames under earthquake loading. Eng. Struct. 2019, 201, 109575. [CrossRef]

56. Xiao, J.; Zhang, K.; Akbar Nezhad, A. Variability of stress-strain relationship for recycled aggregate concrete under uniaxial compression loading. J. Clean. Prod. 2018, 181, 753-771. [CrossRef]

57. Xia, B.; Ding, T.; Xiao, J. Life cycle assessment of concrete structures with reuse and recycling strategies: A novel framework and case study. Waste Manag. 2020, 105, 268-278. [CrossRef]

58. Xiao, J.; Chen, Z.; Ding, T.; Xia, B. Effect of recycled aggregate concrete on the seismic behavior of DfD beam-column joints under cyclic loading. Adv. Struct. Eng. 2020. [CrossRef]

59. Xu, J.; Zhao, X.; Yu, Y.; Xie, T.; Yang, G.; Xue, J. Parametric sensitivity analysis and modelling of mechanical properties of normaland high-strength recycled aggregate concrete using grey theory, multiple nonlinear regression and artificial neural networks. Constr. Build. Mater. 2019, 211, 479-491. [CrossRef]

60. Yang, H.F.; Deng, Z.H.; Huang, Y. Analysis of Stress-Strain Curve on Recycled Aggregate Concrete under Uniaxial and Conventional Triaxial Compression. Adv. Mater. Res. 2010, 168-170, 900-905. [CrossRef]

61. Youfu, Y.A.N.G. Performance of recycled aggregate concrete-filled steel tubular members under various loadings. In Proceedings of the 2nd International Conference on Waste Engineering and Management; ICWEM-RILEM Publications SARL: Shanghai, China, 2010.

62. Younis, K.H.; Mustafa, S.M. Feasibility of Using Nanoparticles of SiO2 to Improve the Performance of Recycled Aggregate Concrete. Adv. Mater. Sci. Eng. 2018, 2018, 1-11. [CrossRef] [PubMed]

63. Yue, Y.; Zhou, Y.; Xing, F.; Gong, G.; Hu, B.; Guo, M. An industrial applicable method to improve the properties of recycled aggregate concrete by incorporating nano-silica and micro-CaCO. J. Clean. Prod. 2020, 259, 120920. [CrossRef]

64. Neville, A.M. Properties of Concrete; Prentice Hall: Hoboken, NJ, USA, 1995.

65. Neville, A.M.; Brooks, J.J. Concrete Technology, 2nd ed.; Harlow, Pearson Educ. Ltd.: New York, NY, USA, 2010.

66. Silva, R.V.; De Brito, J.; Dhir, R.K. Properties and composition of recycled aggregates from construction and demolition waste suitable for concrete production. Constr. Build. Mater. 2014, 65, 201-217. [CrossRef]

67. Silva, R.V.; de Brito, J.; Dhir, R.K. Establishing a relationship between modulus of elasticity and compressive strength of recycled aggregate concrete. J. Clean. Prod. 2016, 112, 2171-2186. [CrossRef]

68. BS EN 1992-1-1 Eurocode 2: Design of concrete structures-Part 1-1: General rules and rules for buildings. Br. Stand. Inst. 2004, 1, 230. 
69. Silva, R.; De Brito, J.; Dhir, R. The influence of the use of recycled aggregates on the compressive strength of concrete: A review. Eur. J. Environ. Civ. Eng. 2014, 19, 825-849. [CrossRef]

70. Bisht, A.; Gerber, J.-F. Ecological distribution conflicts (EDCs) over mineral extraction in India: An overview. Extr. Ind. Soc. 2017, 4, 548-563. [CrossRef] 